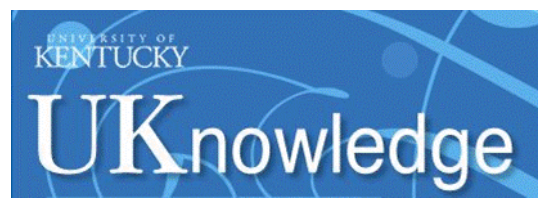

University of Kentucky

UKnowledge

\title{
Violence against Women Raises Risk of Cervical Cancer
}

Ann L. Coker

University of Kentucky, ann.coker@uky.edu

Claudia Hopenhayn

University of Kentucky, cmhope0@uky.edu

Christopher P. DeSimone

University of Kentucky, christopher.desimone@uky.edu

Heather M. Bush

University of Kentucky, heather.bush@uky.edu

Leslie Crofford

University of Kentucky, Icrofford@uky.edu

Follow this and additional works at: https://uknowledge.uky.edu/crvaw_facpub

Part of the Obstetrics and Gynecology Commons, Psychology Commons, Public Health Commons, Social Work Commons, and the Sociology Commons

Right click to open a feedback form in a new tab to let us know how this document benefits you.

\section{Repository Citation}

Coker, Ann L.; Hopenhayn, Claudia; DeSimone, Christopher P.; Bush, Heather M.; and Crofford, Leslie, "Violence against Women Raises Risk of Cervical Cancer" (2009). CRVAW Faculty Journal Articles. 107. https://uknowledge.uky.edu/crvaw_facpub/107

This Article is brought to you for free and open access by the Center for Research on Violence Against Women at UKnowledge. It has been accepted for inclusion in CRVAW Faculty Journal Articles by an authorized administrator of UKnowledge. For more information, please contact UKnowledge@lsv.uky.edu. 


\section{Violence against Women Raises Risk of Cervical Cancer}

Digital Object Identifier (DOI)

http://dx.doi.org/10.1089/jwh.2008.1048

\section{Notes/Citation Information}

This is a copy of an article published in the Journal of Women's Health $\odot 2009$ Mary Ann Liebert, Inc.; Journal of Women's Health is available online at: http://online.liebertpub.com/loi/jwh 


\title{
Violence against Women Raises Risk of Cervical Cancer
}

\author{
Ann L. Coker, Ph.D., Claudia Hopenhayn, Ph.D., ${ }^{2}$ Christopher P. DeSimone, M.D., \\ Heather M. Bush, Ph.D., ${ }^{2}$ and Leslie Crofford, M.D. ${ }^{3}$
}

\begin{abstract}
Background: An emerging literature suggests that violence against women (VAW), particularly sexual violence, may increase the risk of acquiring a sexually transmitted infection (STI) and, therefore, may be associated with cervical cancer development. The purpose of this cross-sectional analysis was to determine if women who had experienced violence had higher prevalence rates of invasive cervical cancer.

Methods: Women aged 18-88 who joined the Kentucky Women's Health Registry (2006-2007) and completed a questionnaire were included in the sample. Multivariate logistic regression analyses were used to adjust odds ratio (OR) for confounders (e.g., age, education, current marital status, lifetime illegal drug use, and pack-years of cigarette smoking).

Results: Of 4732 participants with no missing data on violence, cervical cancer, or demographic factors, 103 (2.1\%) reported ever having cervical cancer. Adjusting for demographic factors, smoking, and illegal drug use, experiencing VAW was associated with an increased prevalence of invasive cervical cancer (adjusted OR $[\mathrm{aOR}]=2.6,95 \% \mathrm{CI}=1.7-3.9)$. This association remained significant when looking at three specific types of VAW: intimate partner violence (IPV) $(\mathrm{aOR}=2.7,95 \% \mathrm{CI}=1.8-4.0)$, adult exposure to forced sex $(\mathrm{aOR}=2.6,95 \%$ $\mathrm{CI}=1.6-4.3)$, and child exposure to sexual abuse $(\mathrm{aOR}=2.4,95 \% \mathrm{CI}=1.4-4.0)$.

Conclusions: Rates of cervical cancer were highest for those experiencing all three types of VAW relative to those never experiencing VAW. Because VAW is common and has gynecological health effects, asking about VAW in healthcare settings and using this information to provide tailored healthcare may improve women's health outcomes.
\end{abstract}

\section{Introduction}

$\mathbf{V}$ IOLENCE AGAINST WOMEN (VAW) is defined by the United Nations (UN) as "any act of gender-based violence that results in, or is likely to result in, physical, sexual, or psychological harm or suffering to women, including threats of such acts, coercion or arbitrary deprivation of liberty, whether occurring in public or private life."1 Male VAW has been associated with both psychological and physical morbidity for girls and women. ${ }^{2-4}$ Specifically, girls exposed to sexual abuse are at increased risk of substance use, ${ }^{5,6}$ adolescent pregnancy, ${ }^{7}$ and subsequent sexual risk-taking behaviors. ${ }^{8}$ Sexually abused girls are also at increased risk of forced sex during young adulthood. ${ }^{9}$

Women who are forced into sexual activities in childhood or adulthood are also at increased risk of developing sexually transmitted infections (STI), ${ }^{10}$ including human papilloma- virus (HPV) infection. ${ }^{11}$ Persistent high-risk HPVs are the necessary etiological agent for cervical neoplasia development $^{12}$ and occur in almost $100 \%$ of cervical cancer cases. ${ }^{13}$ Sexual abuse, including coercive sexual experiences, has been linked to both high-risk HPV and cervical squamous intraepithelial lesions in college women ${ }^{14}$ and among women prisoners. ${ }^{15}$ Risk of an STI has consistently been associated with intimate partner violence (IPV) and particularly with sexual violence. ${ }^{3,16-21}$ Finally, IPV has been correlated with an increased risk of preinvasive cervical neoplasia in three ${ }^{22-24}$ of five studies. ${ }^{22-26}$ Only one study has explored and found an association between IPV and invasive cervical cancer. ${ }^{24}$ This study lacked sufficient power $(n=1152)$ to provide an accurate estimate of the odds of cervical cancer given exposure to violence.

The present cross-sectional analysis of the Kentucky Women's Health Registry (KWHR) will add to the existing

\footnotetext{
${ }^{1}$ Department of Obstetrics and Gynecology, University of Kentucky, Lexington, Kentucky.

${ }^{2}$ College of Public Health, University of Kentucky, Lexington, Kentucky.

${ }^{3}$ Department of Internal Medicine, University of Kentucky, Lexington, Kentucky.
} 
literature by addressing the association between VAW and cervical cancer in a much larger sample. This analysis will also add to the literature by comprehensively defining violence against women as our primary exposure. IPV frequently cooccurs with child and adult sexual abuse; thus, we defined VAW to include the lifetime experiences of IPV, forced sex, and child sexual abuse. We hypothesized that women who were exposed to VAW would have higher rates of cervical cancer than would women who were never exposed. Further, because cigarette smoking interacts with HPV to increase the risk of cervical neoplasia ${ }^{27}$ and women experiencing VAW are significantly more likely to smoke, ${ }^{28}$ we hypothesized that smokers exposed to VAW will have the highest cervical cancer rates.

\section{Materials and Methods}

\section{Data source}

We conducted a cross-sectional analysis of data available from the KWHR. The registry, begun in 2006, is a comprehensive survey open to all women, aged $\geq 18$ years, living in Kentucky. The purpose of the registry is to better care for Kentucky women by understanding how risk and protective behavioral factors may differentially affect women's health and to give interested women the chance to participate in medical research. The goal of the survey is to enroll over 25,000 Kentucky women over the next 10 years. Women were invited to participate in the KWHR through a range of advertisement venues. KWHR brochures are available at the University of Kentucky in Lexington in all clinics providing care to women. Registry staff work across the state to recruit women through state and county health departments, county agricultural extension offices, private physicians' offices, women's professional organizations, and homemaker organizations. Women can complete the survey online (www.mc .uky.edu/Kyhealthregistry) or by completing a pen and paper version of the same survey and mailing the form to the KWHR.

Because this is a large convenience sample of volunteers, we do not have a refusal rate for participation. The KWHR survey data are designed as a cohort study. Women are asked to complete the survey annually. To date (May 2009), 4916 women aged $\geq 18$ have completed at least one initial survey to enroll in the KWHR, and the number of women returning to complete the survey a second or third time is approximately $63 \%$. The majority of women complete this survey online using a secured website; however, $12.7 \%$ completed and mailed a paper version of the survey. The KWHR was approved by the University of Kentucky Institutional Review Board. Consent and the Health Insurance Portability and Accountability Act (HIPAA) were obtained for all participants.

In this analysis, we focused on women who completed the baseline (first) survey. Of the 4916 women, 59 were excluded because of missing data on IPV, child abuse, or other forced sex, and 128 were excluded because of additionally missing data on smoking status, other substance use, or demographic data. The final number for these analyses is 4732 .

\section{Cervical cancer}

Women were asked to provide details about all previous cancer diagnoses, including cervical cancer. No age at diagnosis data are available. All data are self-reported, and given consent issues, the data cannot be verified by medical records. A dichotomous variable was created to indicate a history of ever having had cervical cancer (hereafter, cervical cancer prevalence).

\section{Violence against women}

Five items were used to measure lifetime exposure to VAW. We operationally defined VAW as IPV or forced sexual experiences as an adult or during childhood. Three items were used to measure IPV: for physical IPV: Has an intimate partner hit, kicked, punched, or otherwise hurt you?; for sexual IPV: Has an intimate partner used force (like hitting, holding down, or using a weapon) to make you have sex?; for stalking: Has an intimate partner ever repeatedly followed you, spied on you, made unsolicited phone calls to your place of work or at home, damaged your property, or stalked you in any way? Although answers to these questions included experiences in the past year as well as lifetime experiences, we grouped the positive responses to indicate lifetime IPV because we do not know the age at cervical cancer development, nor do we know the age at first IPV. We created one dichotomous variable for each of the three IPV types, as well as an indicator variable for having experienced any of the three types of IPV. One item measured childhood sexual abuse: When you were a child, did any parent, stepparent, guardian or any other person make you have sex (any sex act, not just intercourse) by using force or by threatening to harm you or someone close to you? One item was included to assess if the woman had ever experienced forced sex by someone other than an intimate partner: Has anyone other than an intimate partner or anyone else used force (like hitting, holding down, or using a weapon) to make you have sex? Again, responses were dichotomized.

Women may have experienced multiple forms of VAW during their lifetime; the combined effects of violence as a child and adult may increase the risk of STIs and cervical cancer. Therefore, we created the following categories of VAW: experiencing all three forms, experiencing any two of the three forms, and experiencing any one of the three forms. The referent group for these categories was those women who never experienced VAW.

\section{Potential confounders/effect modifiers}

The KWHR includes the following sets of variables used here as either potential confounders or effect modifiers. Demographic factors included were age (continuous variable), current marital status, race/ethnicity (white non-Hispanic vs. other), education (ordinal variable ranging from no high school diploma through postgraduate education), and private health insurance coverage (current private health insurance vs. no private health insurance). Smoking was characterized as lifetime smoking status (dichotomous variable), duration of smoking (age at first and last smoking), and pack-years of smoking. Pack-years are based on years of smoking and the average number of packs of cigarette usually smoked per day. Illegal drug use was defined as ever having used cocaine, heroin, methamphetamines, or ecstasy (dichotomous variable). The survey included a question characterizing lifetime Pap smear screening frequency, but we chose not to include this variable because we do not know the screening patterns prior to cervical cancer development. Further Pap screening 
recommendations change after cervical cancer diagnosis and treatment.

Smoking, along with high-risk HPV, is an etiological factor in cervical cancer development. Therefore, effect modification by smoking was evaluated for the relationship between VAW exposure and cervical cancer prevalence. The following combined exposure groupings were used: (1) VAW $(+)$ and smoking (+), (2) VAW (+) and smoking (-), (3) VAW (-) and smoking $(+)$, compared with VAW $(-)$ and smoking $(-)$ as the referent group.

\section{Statistical analysis}

Chi-square tests were performed for dichotomous analyses, and $t$ tests were used for continuous and ordinal outcomes (e.g., age, years smoked, and pack-years of smoking). Decisions about the inclusion of confounders were based on the variable being association with VAW, being known risk factors for cervical cancer, and not being in the causal pathway between VAW and cervical cancer. Given the large sample size, only associations with VAW of $p<0.01$ were noted. Given the small number of cervical cancer cases, we explored additive interactions and used multivariate models to adjust for other confounders.

\section{Results}

Lifetime prevalence of VAW among those completing the KWHR was relatively high (41.1\%). In this sample, $35.9 \%$ experienced IPV, $9.7 \%$ of women reported forced sex by someone other than an intimate partner during their adult life, and $8.4 \%$ experienced sexual abuse during their childhood. Further, among the 1700 women who had ever experienced IPV, $20.2 \%$ reported forced sex and $13.8 \%$ reported child sexual abuse.
Compared with women never experiencing VAW, those who had ever experienced VAW were significantly younger, had less education, and were less likely to currently have private health insurance and to be married $(p<0.01)$ (Table 1$)$. Additionally, women experiencing VAW were significantly more likely to have ever had an STI, to have ever used illegal drugs, to smoke cigarettes, and to smoke more cigarettes over a longer period than those never experiencing VAW. The following factors were included as confounders in subsequent multivariate models: age, education, current marital status, lifetime illegal drug use, and pack-years of cigarette smoking. Our two indicators of socioeconomic status (SES), current health insurance and education, were correlated (coefficient $=0.292, p<0.0001$ ). We opted to include education level in multivariate models because educational attainment reflects lifetime status vs. current SES. We did not have a measure of SES at the time of cervical cancer development. History of having an STI was not included as a confounder because it may be in the causal pathway from VAW (particularly sexual) and cervical cancer.

Table 2 presents the multivariate logistic regression analysis estimating odds ratios (ORs) for cervical cancer and all forms of VAW combined and by three types of VAW: IPV, forced sex by nonpartner, and child sexual abuse. Two percent $(n=103)$ of the 4732 women included in this analysis reported ever having cervical cancer. Among the 1945 women who had ever experienced VAW, 3.5\% had ever had cervical cancer, compared with $1.3 \%$ of women never experiencing VAW $(\mathrm{aOR}=2.6,95 \% \mathrm{CI} 1.7-3.9)$. Cervical cancer rates were also higher for women experiencing IPV $(\mathrm{aOR}=2.7,95 \% \mathrm{CI}$ $1.8-4.0)$, forced sex by a nonpartner $(\mathrm{aOR}=2.6,95 \% \mathrm{CI} 1.6-$ 4.0 ), and child sexual abuse ( $\mathrm{aOR}=2.4,95 \% \mathrm{CI} 1.4-4.0)$.

When summing the total number of the three possible VAW types queried (e.g., IPV, child sexual abuse, and forced sex by a nonpartner), there was a trend of increasing cervical

Table 1. Demographic and Risk Factors and Lifetime Violence Against Women (VAW), N=4732

\begin{tabular}{|c|c|c|c|}
\hline & \multicolumn{2}{|c|}{$\begin{array}{l}\% \text { with risk factor by } \\
\text { lifetime VAW status }\end{array}$} & \multirow{2}{*}{$\begin{array}{c}\text { Difference in risk } \\
\text { factor by VAW status }\end{array}$} \\
\hline & $V A W$ & No VAW & \\
\hline Demographic factors & $n=1945$ & $n=2787$ & \\
\hline Mean age (standard error) & $44.89(0.28)$ & $47.37(0.29)$ & $t=-5.92(<0.0001)$ \\
\hline \multicolumn{4}{|l|}{ Highest education } \\
\hline Less than high school & $1.9 \%$ & $0.8 \%$ & \\
\hline High school graduate/GED & $11.1 \%$ & $10.0 \%$ & \\
\hline Some college & $23.8 \%$ & $17.1 \%$ & \\
\hline Associate degree & $12.0 \%$ & $9.2 \%$ & \\
\hline College graduate & $20.3 \%$ & $23.5 \%$ & \\
\hline Postgraduate & $31.0 \%$ & $39.4 \%$ & $t=-7.48(<0.0001)$ \\
\hline Currently have private health insurance & $82.7 \%$ & $91.7 \%$ & chi-square $=86.57(<0.0001)$ \\
\hline Currently married & $54.3 \%$ & $67.1 \%$ & chi-square $=79.41(<0.0001)$ \\
\hline Non-Hispanic white race & $90.5 \%$ & $92.5 \%$ & chi-square $=6.01(0.01)$ \\
\hline \multicolumn{4}{|l|}{ Other cervical cancer risk factors } \\
\hline Women ever told of a sexually transmitted infection & $24.1 \%$ & $12.0 \%$ & chi-square $=118.68(<0.0001)$ \\
\hline Ever used illegal drug ${ }^{\mathrm{a}}$ & $19.0 \%$ & $6.5 \%$ & chi-square $=175.78(<0.0001)$ \\
\hline Ever smoker & $50.4 \%$ & $29.9 \%$ & chi-square $=202.83(<0.0001)$ \\
\hline Mean years smoking ${ }^{\mathrm{b}}$ (standard error) & $8.84(0.29)$ & $5.35(0.19)$ & $t=11.15(<0.0001)$ \\
\hline Mean pack-years ${ }^{\mathrm{b}}$ (standard error) & $7.51(0.29)$ & $4.21(0.21)$ & $t=9.34(<0.0001)$ \\
\hline
\end{tabular}

allegal drugs use includes cocaine, heroin, methamphetamines, or ecstasy.

${ }^{\mathrm{b}}$ Nonsmokers received value of 0 . 
Table 2. Violence against Women and Prevalence of Invasive Cervical Cancer, $N=4732$

\begin{tabular}{|c|c|c|c|}
\hline & \multicolumn{3}{|c|}{ Ever had cervical cancer $(\mathrm{n}=103)$} \\
\hline & $\mathrm{N}$ in strata & $\mathrm{n}(\%)$ & Adjusted odds ratio ${ }^{\mathrm{a}}(95 \% \mathrm{CI})$ \\
\hline \multicolumn{4}{|l|}{ Violence against woman ${ }^{b}$} \\
\hline Ever & 1945 & $68(3.5 \%)$ & $2.6(1.7-3.9)$ \\
\hline Never & 2787 & $35(1.3 \%)$ & 1.0 (referent) \\
\hline \multicolumn{4}{|l|}{ By type of VAW } \\
\hline Any IPV & 1700 & $64(3.8 \%)$ & $2.7(1.8-4.0)$ \\
\hline Sexual IPV & 467 & $26(5.6 \%)$ & $2.7(1.6-4.4)$ \\
\hline Physical IPV & 1158 & $49(4.2 \%)$ & $2.5(1.6-3.7)$ \\
\hline Stalking by an intimate & 1054 & $45(4.3 \%)$ & $2.6(1.7-4.0)$ \\
\hline No IPV & 3032 & $39(1.3 \%)$ & 1.0 (referent) \\
\hline Adult exposure to forced sex by nonpartner & 460 & $25(5.4 \%)$ & $2.6(1.6-4.3)$ \\
\hline No forced sex & 4272 & $77(1.8 \%)$ & 1.0 (referent) \\
\hline Child exposure to sexual abuse & 397 & $20(5.0 \%)$ & $2.4(1.4-4.0)$ \\
\hline No child sexual abuse & 4335 & $83(1.9 \%)$ & 1.0 (referent) \\
\hline \multicolumn{4}{|c|}{ Number of types of VAW experienced over life span } \\
\hline Experienced all three types of VAW & 122 & $10(8.2 \%)$ & $6.4(2.7-14.9)$ \\
\hline Experienced two types & 368 & $21(5.7 \%)$ & $4.0(2.2-7.3)$ \\
\hline Experienced one type ${ }^{\mathrm{d}}$ & 1455 & $37(2.5 \%)$ & $1.9(1.2-3.1)$ \\
\hline \multirow[t]{2}{*}{ Never experienced VAW } & 2787 & $35(1.3 \%)$ & 1.0 (referent) \\
\hline & & $p$ for trend & chi-square $=7.39(0.007)$ \\
\hline
\end{tabular}

${ }^{\mathrm{a} O d d s}$ ratio (aOR) adjusted for age, education, current marital status, pack-years smoking, ever used an illegal drug.

${ }^{\mathrm{b}}$ Defined to include ever experiencing stalking, physical or sexual abuse within a partnership, adult exposure to forced sex by someone other than a partner, or child exposure to sexual abuse.

${ }^{\mathrm{c}} 60.1 \%$ IPV and forced sex by a nonpartner, $30.7 \%$ IPV and child sexual abuse, $9.2 \%$ forced sex by a nonpartner and child sexual abuse.

$\mathrm{d} 85.5 \%$ IPV, $8.8 \%$ child sexual abuse, and $5.7 \%$ forced sex by a nonpartner.

cancer prevalence with increasing types of VAW experienced (chi-square $=7.66, p$ for trend $=0.007$ ). Women who experienced all three types of VAW had the highest cervical cancer rates $(\mathrm{aOR}=6.4,95 \% \mathrm{CI} 2.7-14.9)$ (Table 2$)$.

Lifetime smoking status and VAW appear to interact to increase cervical cancer rates. Among the 980 women who had ever smoked and experienced VAW, 45 women $(4.6 \%)$ had ever had cervical cancer compared with 17 women $(0.9 \%)$ who never smoked or experienced VAW $(\mathrm{aOR}=4.9,95 \% \mathrm{CI}$ 2.6-8.9). Among the 965 women who were never smokers but did experience VAW, 23 (20.4\%) had cervical cancer $(\mathrm{aOR}=2.7,95 \%$ CI 1.4-5.1). Similarly, among the 834 women never experiencing VAW who were smokers, 18 (2.2\%) had ever had cervical cancer $(\mathrm{aOR}=2.3,95 \% \mathrm{CI} 1.1-4.7)$.

\section{Discussion}

To our knowledge, this is the first study to report an association between cervical cancer and three forms of VAW: IPV, exposure to child sexual abuse, and adult forced sex. Experiencing multiple types of VAW increased the prevalence of cervical cancer. Cigarette smoking, an acknowledged cause of cervical cancer, appears to further increase cervical cancer rates in combination with VAW. Because cervical cancer is a rare event, we needed the large sample from the KWHR $(n=4732)$, which has sufficient study power $(95 \%)$ to detect a rate ratio of 2.0 with a cervical cancer prevalence in the population of $2.0 \%$. We were able to measure both physical and sexual abuse and adjust for confounding factors (e.g., age, education, marital status, smoking, and illegal drug use).

Our finding that all three forms of VAW were associated with cervical cancer is consistent with the growing literature showing that sexual assaults and abuse are associated with an increased risk of an STI, including infection with human immunodeficiency virus (HIV) ${ }^{29}$ and $\mathrm{HPV}^{30}$ and with an increased risk of cervical dysplasia. ${ }^{15,22,24}$

Mechanistically, how might VAW increase the risk of cervical cancer? Figure 1 provides a conceptual model for pathways by which VAW may be associated with cervical cancer. For this analysis, we only had data on VAW, smoking, and cervical cancer; however, it is also plausible that VAW may impact cervical cancer risk through important constructs depicted in Figure 1. For example, VAW, particularly sexual violence, influences a woman's control over her choice to engage in sexual intercourse and use of contraception. Abusive partners may not be monogamous and may also refuse barrier methods of contraception, thus limiting women's ability to protect themselves from STIs, ${ }^{18}$ including HPV. VAW may thus directly influence the risk of cervical cancer through increasing risk of acquiring and maintaining a persistent HPV infection, the necessary event for cervical cancer development. ${ }^{12}$ A consistent literature documents that women experiencing VAW are at increased risk of acquiring an STI. ${ }^{3,19,20,31-42}$ VAW may influence cervical cancer risk indirectly through stress and associated immune suppression. Women experiencing VAW are well documented to have higher self-perceived stress levels and higher rates of depression and anxiety disorders. ${ }^{3}$ Increased stress may affect cervical neoplasia risk through changes to a woman's immune surveillance. ${ }^{4-47}$ Immune compromised subjects are more likely to develop a range of infections, including cervical dysplasia and genital condyloma. ${ }^{48}$ Women infected with HIV are known to be at increased risk of invasive cervical cancer. ${ }^{47}$ Two recent studies indicate that higher stress levels 


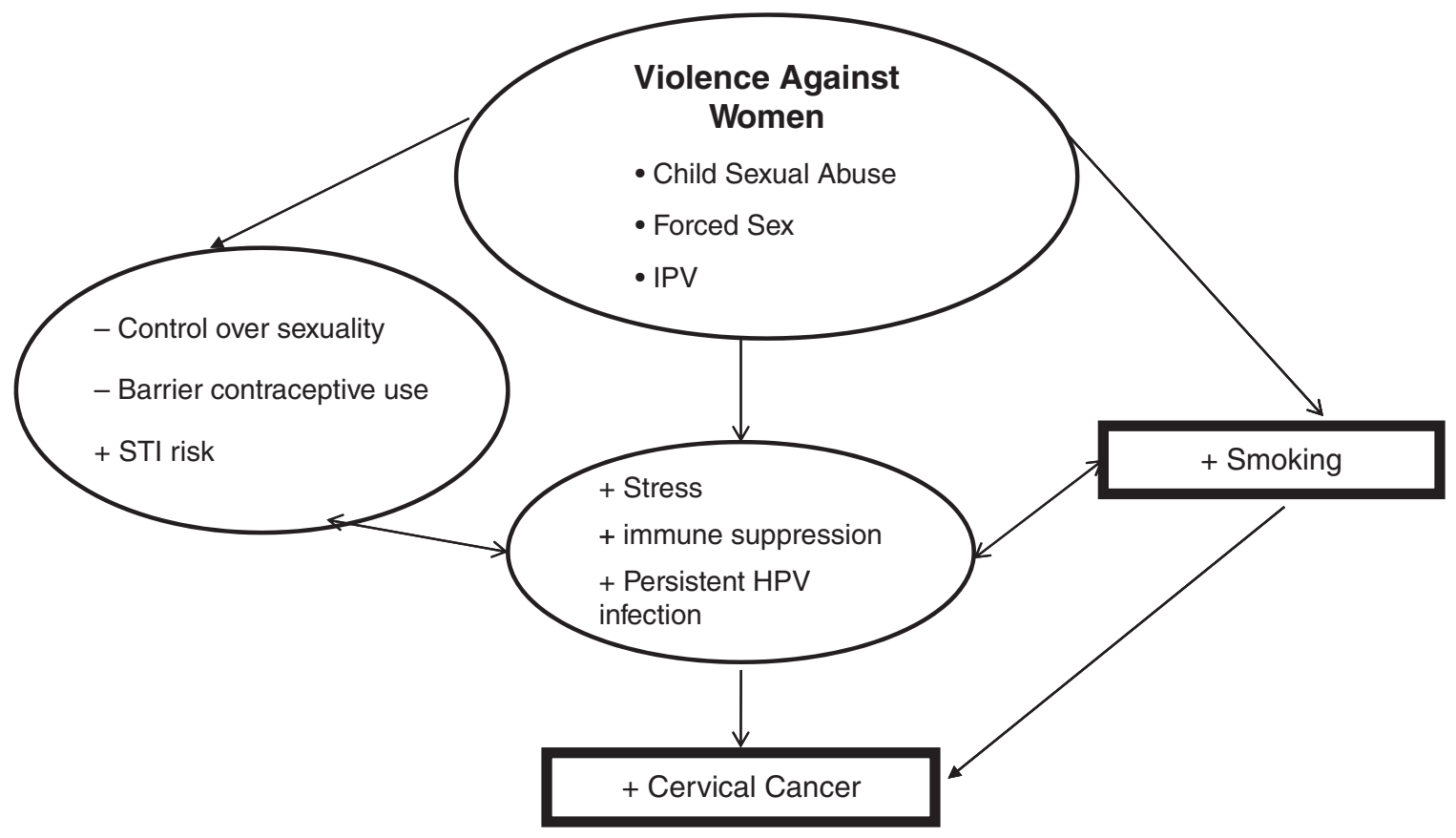

FIG. 1. Conceptual model for VAW and cervical cancer.

increased the odds of cervical neoplasia progression ${ }^{49}$ or being diagnosed with a higher grade lesion. ${ }^{22}$ VAW may influence cervical cancer risk through smoking; women who have experienced VAW are significantly more likely to smoke. ${ }^{28}$ In addition to HPV infection, cigarette smoking has been identified as an important cofactor for development of cervical cancer. ${ }^{13,50}$ Smoking may affect cervical cancer risk by influencing early immune responses to HPV and result in persistent HPV infection. ${ }^{51}$ Smoking and high-risk HPVs biologically interact to cause cervical cancer. ${ }^{27}$ Our finding that women who smoke and were exposed to VAW had the highest cervical cancer rates is consistent with this observation, yet we lack biological measurement of HPV.

Finding that VAW is associated with cervical cancer in this cross-sectional sample suggests that confirmatory results should be sought using a study design better able to address the risk of preinvasive cervical lesions. Future studies are also needed to investigate potential biological mechanisms by which violence heightens the risk for cervical cancer. Additional studies are needed to address the life course of VAW and its potential impact on cervical cancer risk. Such an understanding may inform intervention development to reduce the impact of abuse on cervical cancer risk.

There are limitations to this cross-sectional analysis that deserve mention. It is impossible to infer causality from observational data. As with most cross-sectional analyses, we do not know the timing of VAW relative to cervical cancer development because we do not have dates of violence or cancer occurrence. We can be reasonably certain that child sexual abuse occurred prior to cervical cancer. The greater uncertainty lies with the temporal sequence for IPV and cancer. The average age at first IPV is 25.7 years, ${ }^{52}$ and the mean age at cervical cancer diagnosis was 49.8. (www.bcr.uby.edu). With this information, it is reasonable to conclude that IPV and, likely, forced sex preceded cervical cancer diagnosis for the majority of the cervical cancer cases included in this analysis. Because three VAW items were included in the survey, we cannot define VAW by frequency or duration of the experience. Thus, we cannot, for example, determine whether repeated sexual IPV causes greater odds of cervical cancer. Although multivariate analyses were conducted to adjust for confounders, residual confounding remains a potential bias. Additionally, we have no information on the HPV status or sexual activity of women's male partners. As all measures were based on women's self-report, the cervical cancer diagnosis was not confirmed by any laboratory tests or medical record data.

Selection bias may result from the voluntary nature of the KWHR sample, such that women experiencing VAW may be less likely to participate. The rates of VAW would then be lower in this sample. To explore this possibility, we compared the lifetime rates of physical or sexual IPV based on the KWHR $(24.4 \%)$ with the rate from a report by the Centers for Disease Control and Prevention's Behavioral Risk Factors Surveillance System (BRFSS) of $23.6 \%$ lifetime physical or sexual violence by a current or former intimate partner. ${ }^{53}$ The BRFSS uses a similar approach to defining lifetime IPV, yet subjects are sampled using random digit dial telephone survey methodology. Additionally, the VAW items were included at the end of the survey, and much like the BRFSS survey, VAW was not the focus of the KWHR survey. Finding similar rates provides some evidence that selection bias may not be operational.

The women included in the KWHR are of higher SES than Kentucky women in general. To better describe how this KWHR sample differs from other population-based samples of Kentucky women, we compared the demographic profile of women completing the KWHR survey with Kentucky women who recently completed the Kentucky BRFSS telephone survey. ${ }^{53}$ BRFSS uses a random digit dialing approach 
to sample household to participate in an annual phone-based survey of health behaviors. Based on 2005 BRFSS data for Kentucky women, $17.2 \%$ had no health insurance compared with $12.7 \%$ of women in the KWHR. Women in the KWHR were less likely to have ever smoked (38\%) than were women completing the BRFSS (49\%). However, women in the KWHR were more likely to currently be overweight (59\%) than were women completing the BRFSS (55\%). Because smoking is more prevalent in lower socioeconomic populations, our finding of an association between IPV and cervical cancer in a higher socioeconomic population suggests these findings may be generalized to all women in Kentucky or the United States.

How do the prevalence rates of cervical cancer compare with population-based rates of cervical cancer prevalence in Kentucky? Although Kentucky does have a Surveillance and Epidemiology End Results Registry begun in 1995, this registry has not been collecting both incidence and survival data for sufficient time to accurately calculate prevalence; therefore, we cannot compare our $2 \%$ prevalence in women participating in the KWHR with a population-based estimate for Kentucky women.

From a clinical perspective, VAW is common and does influence gynecological health. Physicians and other healthcare providers caring for women should consider asking women about violence and develop protocols to address the short-term and longer-term consequences of this violence. Efforts to address substance use, including smoking, and other risk-taking behaviors may be important interventions to reduce the risk of subsequent violence revictimization.

\section{Acknowledgments}

We wish to thank Mary Johnson, Dongying Zhong, Ashley McCorkle, Cady Blackey, and Sara Madison Davenport for their work on the KWHR project.

\section{Disclosure Statement}

The authors have no conflicts of interest to report.

\section{References}

1. Declaration on the elimination of violence against women. New York: United Nations, 1994.

2. Koss MP, Bailey JA, Yuan NP, Herrera VM, Lichter EL. Depression, PTSD, and health problems in survivors of male violence: Research and training initiatives to facilitate recovery. Psychol Women Q 2003;27:130-142.

3. Campbell JC. Health consequences of intimate partner violence. Lancet 2002;359:1331-1336.

4. Plichta SB, Falik M. Prevalence of violence and its implications for women's health. Womens Health Issues. 2001;11: 244-258.

5. Bailey JA, McCloskey LA. Pathways to adolescent substance abuse among sexually abused girls. Abnormal Child Psychol 2005;33:39-53.

6. Kilpatrick DG, Acierno R, Saunders BE, Resnick HS, Best CL, Schnurr PP. Risk factors for adolescent substance abuse and dependence: Data from a national sample. J Consult Clin Psychol 2000;68:19-30.

7. Noll JG SC, Putnam KT. Childhood sexual abuse and adolescent pregnancy: A meta-analytic update. Pediatr Psychol 2008;34:366-378.
8. Silverman JG, Raj A, Mucci LA, Hathaway JE. Dating violence against adolescent girls and associated substance use, unhealthy weight control, sexual risk behavior, pregnancy, and suicidality. JAMA 2001;286:572-579.

9. Smith PH, White JW, Holland LJ. A longitudinal perspective on dating violence among adolescent and college-age women. Am J Public Health 2003;93:1104-1109.

10. Trent $M$, Clum $G$, Roche KM. Sexual victimization and reproductive health outcomes in urban youth. Ambulatory Pediatr 2007;7:313-316.

11. Moscicki AB. Genital HPV infections in children and adolescents. Obstet Gynecol Clin North Am 1996;23:675-697.

12. Schiffman M, Castle PE, Jeronimo J, Rodriguez AC, Wacholder S. Human papillomavirus and cervical cancer. Lancet 2007;370:890-907.

13. Bosch FX, de Sanjosé S. The epidemiology of human papillomavirus infection and cervical cancer. Dis Markers 2007; 23:213-227.

14. Kahn JA, Huang B, Rosenthal SL, Tissot AM, Burk RD. Coercive sexual experiences and subsequent human papillomavirus infection and squamous intraepithelial lesions in adolescent and young adult women. Adolesc Health 2005;36:363-371.

15. Coker AL, Patel N, Krishnawami S, Schmidt W, Richter D. Childhood forced sex and cervical neoplasia among women prison inmates. Violence Against Women 1998;4:595-608.

16. McFarlane J, Malecha A, Watson $\mathrm{K}$, et al. Intimate partner sexual assault against women: Frequency, health consequences, and treatment outcomes. Obstet Gynecol 2005;105: 99-108.

17. Coker AL, Smith PH, Bethea L, King MR, McKeown RE. Physical health consequences of physical and psychological intimate partner violence. Arch Fam Med 2000;9:451-457.

18. Garcia-Moreno C, Jansen HAFM, Ellsberg M, Heise L, Watts C, WHO Multicountry Study on Women's Health and Domestic Violence against Women Geneva, Switzerland: WHO, 2006.

19. Martin SL, Matza LS, Kupper LL, Thomas JC, Daly M, Cloutier S. Domestic violence and sexually transmitted diseases: The experience of prenatal care patients. Public Health Rep 1999;114:262-268.

20. Plichta SB, Abraham C. Violence and gynecologic health in women 50 years old. Am J Obest and Gynecol 1996;174:903907.

21. Vos T, Astbury J, Piers LS, et al. Measuring the impact of intimate partner violence on the health of women in Victoria, Australia. Bull WHO 2006;84:739-744.

22. Coker AL, Bond S, Madeleine MM, Luchok K, Pirisi L. Psychosocial stress and cervical neoplasia risk. Psychosom Med 2003;65:644-651.

23. Quinlivan JA, Petersen RW, Davy M, Evans SF. Abnormal Pap smears in teenage mothers and the association with domestic violence, homelessness, and Chlamydia. J Lower Genital Tract Dis 2004;8:112-117.

24. Coker AL, Sanderson M, Fadden MK, Pirisi L. Intimate partner violence and cervical neoplasia. J Womens Health 2000;9:1015-1023.

25. John R, Johnson JK, Kukreja S, Found M, Lindow SW. Domestic violence: Prevalence and association with gynaecological symptoms. Br J Obstet Gynaecol 2004;111:11281132.

26. Letourneau EJ, Holmes M, Chasedunn-Roark J. Gynecologic health consequences to victims of interpersonal violence. Womens Health Issues 1999;9:115-120. 
27. Gunnell AS, Tran TN, Torrång A, Dickman PW, Sparén P, Palmgren J, Ylitalo N. Synergy between cigarette smoking and human papillomavirus type 16 in cervical cancer in situ development. Cancer Epidemiol Biomarkers Prev 2006;15: 2141-2147.

28. Gerber MR, Ganz ML, Lichter E, Williams CM, McCloskey LA. Adverse health behaviors and the detection of partner violence by clinicians. Arch Int Med 2005;165:1016-1021.

29. Zierler S, Feingold L, Laufer D, Velentgas P, Gordon L, Meyer K. Adult survivors of childhood sexual abuse and subsequent risk of HIV infection. Am J Public Health 1991; 81:572-575.

30. Gutman LT, St Claire K, Herman-Giddens ME, Johnston WW, Phelps WC. Evaluation of sexually abused and nonabused young girls for intravaginal human papillomavirus infection. Am J Dis Child 1992;146:694-699.

31. Aubenbraun M, Wilson TE, Allister L. Domestic violence reported by women attending a sexually transmitted disease clinic. Sex Transm Dis 2001;28:143-147.

32. Champion JD, Piper J, Holden A, Korte J, Shain RN. Abused women and risk for pelvic inflammatory disease. West J Nurs Res 2004;26:176-191.

33. Coker AL, Sanderson M, Dong B. Partner violence during pregnancy and risk of adverse pregnancy outcomes. Pediatr Perinat Epidemiol 2004;18:260-269.

34. El-Bassel N, Gilbert L, Krishnan S, et al. Partner violence and sexual HIV-risk behaviors among women in an inner-city emergency department. Violence Vict 1998;13:377-93.

35. King EA, Britt R, McFarlane JM, Hawkins C. Bacterial vaginosis and Chlamydia trachomatis among pregnant abused and nonabused Hispanic women. J Obstet Gynecol Neonat Nurs 2000;29:606-612.

36. Martin SL, Kilgallen B, Tsui AO, Maitra K, Singh KK, Kupper LL. Sexual behaviors and reproductive health outcomes: Associations with wife abuse in India. JAMA 1999; 282:1967-1972.

37. Raj A, Liu R, McCleary-Sills J, Silverman JG. South Asian victims of intimate partner violence more likely than nonvictims to report sexual health concerns. J Immigrant Health 2005;7:85-91.

38. Schei B. Physically abusive spouse-A risk factor of pelvic inflammatory disease? Scand J Primary Health Care 1991;9: $41-45$.

39. Johnson PJ, Hellerstedt WL. Current or past physical or sexual abuse as a risk marker for sexually transmitted disease in pregnant women. Perspect Sex Reprod Health 2002;34:62-67.

40. Muelleman RL, Lenaghan PA, Pakieser RA. Nonbattering presentations to the ED of women in physically abusive relationships. Am J Emerg Med 1998;16:128-131.

41. Bauer HM, Gibson P, Hernandez M, Kent C, Klausner J, Bolan $\mathrm{G}$. Intimate partner violence and high-risk sexual behaviors among female patients with sexually transmitted diseases. Sex Transm Dis 2002;29:411-416.

42. Wu E, El-Bassel N, Witte SS, Gilbert L, Chang M. Intimate partner violence and HIV risk among urban minority women in primary health care settings. AIDS Behav 2003;7:291-301.
43. Goodkin K, Antoni MH, Blaney PH. Stress and hopelessness in the promotion of cervical intraepithelial neoplasia to invasive squamous cell carcinoma of the cervix. J Psychosom Res 1986;30:67-76.

44. Goodkin K, Blaney N, Feaster D, et al. Active coping style is associated with natural killer cell cytotoxicity in asymptomatic HIV-1 seropositive homosexual men. J Psychosom Res 1992;36:635-650.

45. Goodkin K, Antoni MH, Helder L, Sevin B. Psychoneuroimmunological aspects of disease progression among women with human papillomavirus-associated cervical dysplasia and human immunodeficiency virus type 1 coinfection. Int J Psychiatry Med 1993;23:119-148.

46. Antoni $\mathrm{MH}$, Goodkin $\mathrm{K}$. Host moderator variables in the promotion of cervical neoplasia-I. Personality facets. I Psychosom Res 1988;32:327-338.

47. Minkoff H, DeHovitz J. Care of women infected with human immmunodeficiency virus. JAMA 1991;266:2253-2258.

48. Koutsky LA, Holmes KK, Critchlow CW, et al. A cohort study of the risk of cervical intraepithelial neoplasia grade 2 or 3 in relation to papillomavirus infection. $\mathrm{N} \mathrm{Engl} \mathrm{J} \mathrm{Med}$ 1992;327:1272-1278.

49. Pereira DB, Antoni MH, Danielson A, et al. Life stress and cervical squamous intraepithelial lesions in women with human papillomavirus and human immunodeficiency virus. Psychosom Med 2003;65:427-434.

50. International Collaboration of Epidemiological Studies of Cervical Cancer. Comparison of risk factors for invasive squamous cell carcinoma and adenocarcinoma of the cervix: Collaborative reanalysis of individual data on 8,097 women with squamous cell carcinoma and 1,374 women with adenocarcinoma from 12 epidemiological studies. Int J Cancer 2007;120:885-891.

51. Wiley DJ, Wiesmeier E, Masongsong E, et al. Smokers at higher risk for undetected antibody for oncogenic human papillomavirus type 16 infection. Cancer Epidemiol Biomarkers Prev 2006;15:915-920.

52. Tjaden $\mathrm{P}$, Thoennes N. Prevalence, incidence, and consequences of violence against women: Findings from the National Violence Against Women Survey. Washington, DC: U.S. Department of Justice, Office of Justice Programs, NCJ 172837, 1998.

53. BRFSS, 2002. Available at chfs.ky.gov/NR/rdonlyres/ 38ED0768-1D60-405A-AC2E-4DA764100B41/0/2002report. pdf

Address correspondence to: Ann L. Coker, Ph.D. Department of Obstetrics and Gynecology Center for Research on Violence against Women University of Kentucky 800 Rose Street, C-371 Lexington, KY 40536-0293 E-mail: ann.coker@uky.edu 